\title{
Postural Risk, Upper Extremity Stability and Hand Dexterity in Rifle Shooters
}

\author{
Ajit Dabholkar and Sabina Dudekula
}

\begin{abstract}
Aim: To identify the correlation between postural risk, upper extremity stability and hand dexterity in Rifle shooters. Method: This study was a cross sectional study with a sample of 34 subjects. All subjects were professional $10 \mathrm{~m}$ air rifle shooters who fulfilled the inclusion and exclusion criteria. Each subject were assessed for postural stability using [Rapid Upper Limb Assessment (RULA) scale and Rapid Entire Body Assessment (REBA) scale], their hand dexterity was assessed using different tasks in purdue pegboard. Closed kinetic chain upper extremity stability test (CKCUEST) was used to assess upper extremity stability. Results: The observed data was analyzed using GraphPad Instat Version 3.0 using paired t-test. Means and standard deviations were calculated for each demographic data. Correlation were observed between postural risk using (RULA scale and REBA scale) and upper extremity stability in rifle shooters; correlation between upper extremity stability and hand dexterity in rifle shooters; and correlation between postural risk using (RULA and REBA scale) and hand dexterity in rifle shooters were observed. Conclusion: Correlational analysis showed that the rifle shooters are at postural risk with respect to their standing shooting stance (right limbs> left limbs). Significant correlation was found between normalized score and power score of upper extremity stability. Significant correlation was found between Normalized score of CKCUEST and hand dexterity.
\end{abstract}

\section{Ajit Dabholkar}

Professor \& Head (Sports Physiotherapy)

School of Physiotherapy

D.Y. Patil University

Nerul, Navi Mumbai,India

Email: ajitdabholkar1211@gmail.com

Sabina Dudekula

Masters in Sports Physiotherapy (2 $2^{\text {nd }}$ year)

School of Physiotherapy

D.Y. Patil University

Nerul, Navi Mumbai.

Email: sabinadudekula@gmail.com
Keywords: 10m Air rifle Shooting, Rifle Shooters, Postural Risk, Upper Extremity Stability, Hand Dexterity

DOI: 10.18376/jesp/2019/v15/ i2/153523

\section{Introduction}

$10 \mathrm{~m}$ air rifle shooting is a shooting event where the shooter shoots at a target placed over a distance of $10 \mathrm{~m}$ in a standing position using an air rifle which weighs over approximately $5.5 \mathrm{~kg}$ maximum (12.13 lbs). The shooter is allowed to wear a specialized clothing which improves the balance and stability of his stance and prevents chronic back injury which can be due to asymmetric offset load on the spine while the shooter holds the rifle in position. Starting from the ground, feet and legs are there to hold the body up, give a direction to the entire position and balance it. Hips are for height of the rifle and give a sturdy platform to put the left elbow onto. It also aids in direction of the position and balances it. Shoulders are for attaching the rifle to the body and otherwise keep relaxed. Right arm/hand gives stability to the rifle and takes care of triggering (Gianikellis 2000.). 


\section{Journal of Exercise Science \& Physiotherapy Vol. 15 No. 2 (July to December) 2019 ISSN: 0973-2020 (Print) $\quad \mathrm{I}_{2} \mathrm{OR}$ Impact Factor $=6.502 \quad$ ISSN: 2454-6089 (Online)}

This is the standard position of the shooters for $10 \mathrm{~m}$ air rifle shooting. Accordingly, when the shooters place their rifle in position which is an added load to the shoulders and spine, the body is prone to risk of postural injuries. As the given time to complete the game is one hour 30 minutes, and lifting $3.5 \mathrm{~kg}-5.5 \mathrm{~kg}$ (standard weight) of rifle repeatedly after every shot, the upper body is placed under high demands of endurance. Thus it becomes imperative to have good stability as well in order to achieve precise shot. This is because the Rifle during triggering is not still, but moves more or less, depending on the stability of the position. Body sway and aim point fluctuation are important in elite rifle shooting and performance errors are highly individual-specific at this standard (Ball K et. al. 2003). Goran Maksimovic (2019) stated that technical aspects like ammunition, equipment, quality of rifle and working conditions also affect the results and overall performance of the shooter. Stability of hold, cleanness of triggering, aiming accuracy, and timing of triggering are the most important predictors of shooting performance (Ihalainen S et. al. 2016). The basic mechanism of the underlying skill of rifle shooting are whole body stabilization and rifle steadiness. Muscles of the body are the underlying supports that provide stability to the weaponshooter system. Consequently, fatigue of the muscles decreases performance by causing tremor, wobble or other instabilities (Selinger 2009). Shooting performance has been characterized by accuracy (i.e., deviation from target), precision (i.e., consistency), and stability of hold (Hoffman MD et. al. 1992). Hand dexterity of individual shooters helps in pulling the trigger action while firing in rifle shooting. Despite of the rifle stability of the shooter, trigger action on time (accuracy) is as important as stability and balance for overall performance. Since this sport demands coordination, upper extremity stability and fine triggering techniques, this study aims to study the correlation between Postural risk, upper extremity stability and hand dexterity in Rifle shooters.

\section{Materials and Method}

This study was a cross sectional study with a sample of 34 subjects. Thirty four $10 \mathrm{~m}$ rifle shooters were included in the study that fulfilled the inclusion criteria amongst which were professional rifle shooters. All the shooters meeting the inclusion criteria signed an informed consent form. Institutional Ethical Committee (IEC) approval was taken prior to the study from the School of Physiotherapy. All the steps in the procedure of the study were explained to the shooters verbally and a demo of the assessments were shown once before giving them a trial prior to their performance. Each subject were assessed for postural stability using [Rapid Upper Limb Assessment (RULA) scale and Rapid Entire Body Assessment (REBA) scale], their hand dexterity was assessed using different tasks in purdue pegboard. Closed kinetic chain upper extremity stability test (CKCUEST) was used to assess upper extremity stability.

Procedure for Posture assessment of Rifle shooters- Rapid upper limb assessment (RULA) scale and Rapid entire body assessment (REBA) scale were filled on observation of the rifle shooters in three angles (Lateral view from right and left, and posterior view). They were observed during their practice session in shooting range.

Rapid upper limb assessment (RULA) scale: Corlett $\mathrm{N}$ et al., (2004) provides an easily calculated rating of musculoskeletal loads in tasks where people have a risk of neck and upper-limb loading. The tool provides a single score as a "snapshot" of the task, which is a rating of the posture, force, and movement required. The risk is calculated into a score of 1 (low) to 7 (high). These scores are grouped into four action levels that provide an indication of the time frame in which it is reasonable to expect risk control to be initiated.

Rapid entire body assessment (REBA) scale: Hignett $\mathrm{S}$ et al., (2004) developed Rapid entire body assessment (REBA) scale to assess the type of unpredictable working postures. Data are collected about the body posture, forces used, type of movement or action, repetition and coupling. REBA provides a quick and easy measure to assess a variety of working postures for risk of work-related musculoskeletal disorders. It divides the body into sections to be coded independently, according to 


\section{Journal of Exercise Science \& Physiotherapy Vol. 15 No. 2 (July to December) 2019 ISSN: 0973-2020 (Print) I I OR Impact Factor $=6.502 \quad$ ISSN: 2454-6089 (Online)}

movement planes and offers a scoring system for muscle activity throughout the entire body, stagnantly, dynamically, fast changing or in an unsteady way and where manual handling may happen which is referred to as a coupling score as it is significant in the loads handling but may not always be using the hands. A final REBA score is generated to give an indication of the level of risk and urgency with which action should be taken (Sue H et. al. 2000). REBA assessment worksheet is divided in two sections as A and B. Section A is neck, trunk and legs analysis comprising of summation of 6 steps which includes neck position, trunk position, legs position and force/load score. Section B is arms and wrists analysis comprising of 7 steps. It is the summation of upper arm position, lower arm position and wrist position and coupling force.

Procedure for assessment of Upper extremity stability in rifle shooters- To assess Upper Extremity Stability, closed kinetic chain upper extremity stability test (CKCUEST) was used. The test was performed in full push-up position and modified push-up position with the hands placed 36 inches apart on strips of black tape. The person reaches with alternating hands across the body to touch the piece of tape under the opposing hand. The number of cross-body touches performed in 15 seconds was recorded. Average of 3 trials was calculated. Normalized score and Power score were calculated using CKCUEST formula (Goldbeck TG et. al. 2000).

Procedure for assessing hand dexterity using purdue pegboard-Perdue Pegboard was used to test Hand dexterity in rifle shooters in this study. Shooters were positioned on a chair with perdue pegboard placed on the table with comfortable seating. Four tasks were given to perform: 1 . Shooters were asked to pick one pin at a time from the right-hand cup on the board and place them in right-handed holes in one line starting from the top hole as quick as possible in 30 seconds using their right hand only. Total number of pins placed in the holes were counted and recorded. Three trials were taken and average of the 3 was calculated. 2. Second task was the same as first but with the left-hand. 3. Shooters were asked to use both the hands to pick the pins from the cups on the perdue pegboard simultaneously and put them in the holes as quickly as possible in 30 seconds. Three trials were taken and average of the 3 was calculated. 4. The fourth task was the assembly making. Shooters were asked to follow the following instructions- "Pick up one pin from the righthanded cup with your right hand. While you are placing it in the top hole in the right-handed row, pick up a washer with your left hand. As soon as the pin has been placed, drop the washer over the pin. While the washer is being placed over the pin with your left hand, pick up a collar with your right hand. While the collar is being dropped over the pin, pick up another washer with your left hand and drop it over the collar. This completes the first 'Assembly' consisting of a pin, a washer, a collar and a washer. While the final washer for the first assembly is being placed with your left hand, start the second assembly immediately by picking up another pin with your right hand. Place it in the next hole; drop a washer over it with your left hand, and so on, completing another assembly. Now take a moment to try a few practice assemblies." Make a straight line of assembly on the board as quick as possible in 1 minute. Three trials were recorded and average was taken. (Perdue pegboard manual model 32020)

The observed data was analyzed using GraphPad Instat Version 3.0 using paired t-test. Means and standard deviations were calculated for each demographic data. Paired t- tests were used to compare differences in postural Rapid Upper Limb Assessment (RULA) scale and Rapid Entire Body Assessment (REBA) scale. Correlation were observed between postural risk using [Rapid Upper Limb Assessment (RULA) scale and Rapid Entire Body Assessment (REBA) scale] and upper extremity stability in rifle shooters; correlation between upper extremity stability and hand dexterity in rifle shooters; and correlation between postural risk using [Rapid Upper Limb Assessment (RULA) scale and Rapid Entire Body Assessment (REBA) scale] and hand dexterity in rifle shooters. 
Journal of Exercise Science \& Physiotherapy Vol. 15 No. 2 (July to December) 2019 ISSN: 0973-2020 (Print) $\quad \mathrm{I}_{2} \mathrm{OR}$ Impact Factor $=6.502 \quad$ ISSN: 2454-6089 (Online)

Results

Table 1. Comparison between Left Rapid Upper Limb Assessment (RULA) and Right Rapid Upper Limb Assessment (RULA)

\begin{tabular}{|l|c|c|c|c|}
\hline Variable & Mean \pm SD & $95 \%$ CI & P value & Significance \\
\hline Left RULA & $6.79 \pm 0.44$ & 6.57 to 6.89 & $0.002 * *$ & VS \\
\hline Right RULA & 7 & 7 & & \\
\hline
\end{tabular}

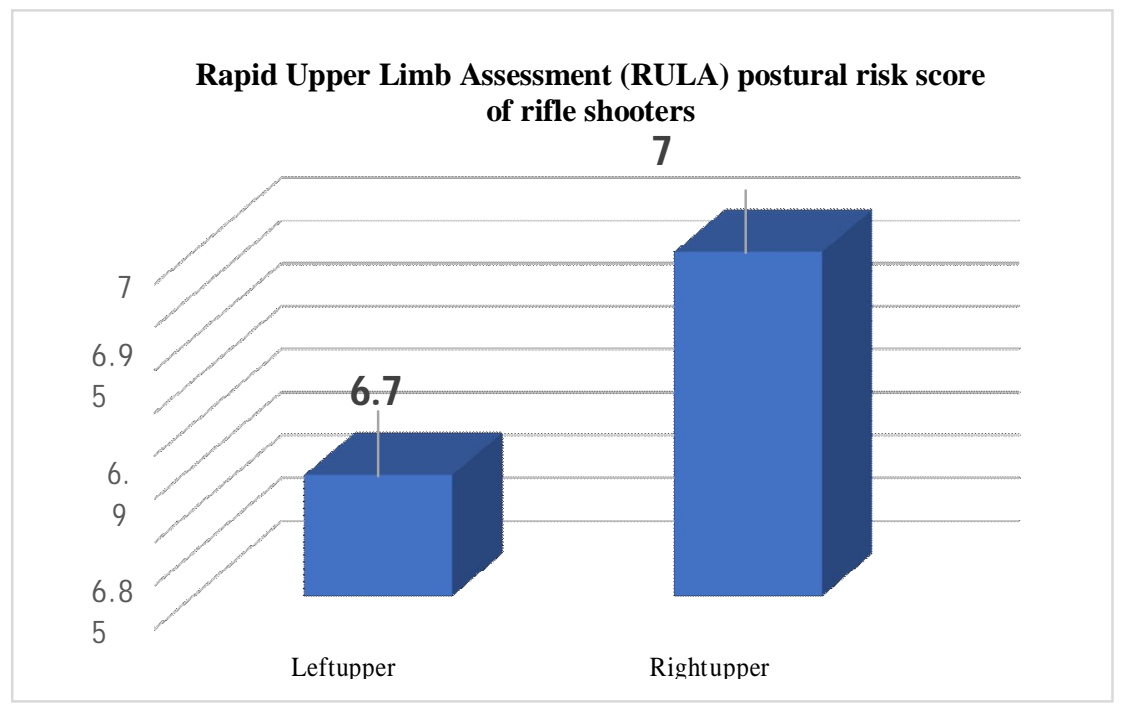

Figure 1. Comparison between Left Rapid Upper Limb Assessment (RULA) and Right Rapid Upper Limb Assessment (RULA)

Table 2. Comparison between Left Rapid Entire Body Assessment (REBA) and Right Rapid Entire Body Assessment (REBA)

\begin{tabular}{|l|c|c|c|c|}
\hline Variable & Mean \pm SD & $95 \%$ CI & P value & Significance \\
\hline Left REBA & $6.97 \pm 0.52$ & 6.78 to 7.15 & $0.00 * *$ & QS \\
\cline { 1 - 3 } Right REBA & $\mathbf{8 . 6 1} \pm 0.77$ & 8.34 to 8.89 & & \\
\hline
\end{tabular}


Journal of Exercise Science \& Physiotherapy Vol. 15 No. 2 (July to December) 2019 ISSN: 0973-2020 (Print) $\quad \mathrm{I}_{2} \mathrm{OR}$ Impact Factor $=6.502 \quad$ ISSN: 2454-6089 (Online)

Rapid Entire Body Assessment (REBA) postural risk score of rifle shooters

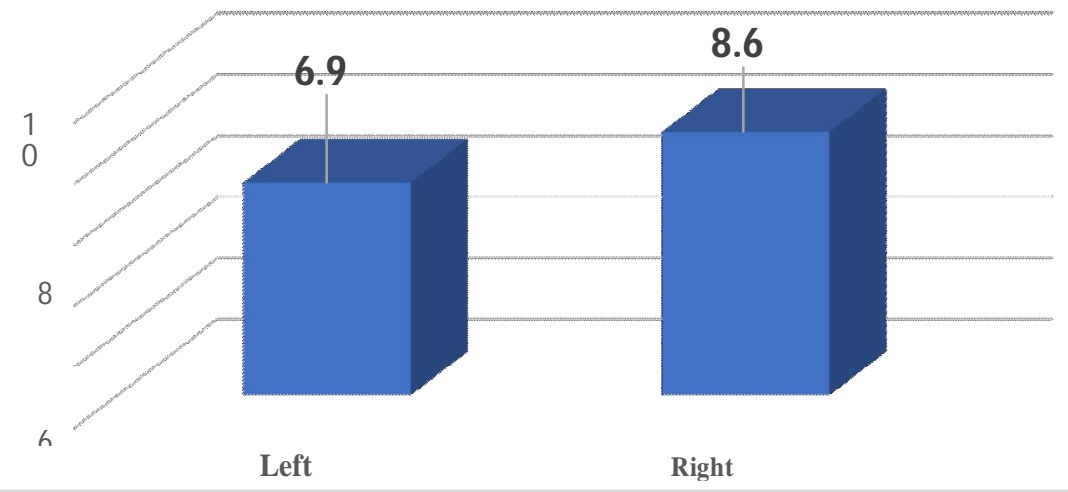

Figure 2. Comparison between Left Rapid Entire Body Assessment (REBA) and Right Rapid Entire Body Assessment (REBA)

Table 3. Correlation between Normalized score of Closed kinetic chain upper extremity stability test (CKCUEST) and Power score Closed kinetic chain upper extremity stability test (CKCUEST)

\begin{tabular}{|c|c|c|c|c|c|c|}
\hline S.No & $\begin{array}{l}\text { Correlation between } \\
\text { variables }\end{array}$ & $\begin{array}{l}\text { Correlation } \\
\text { coefficient }(\mathrm{r})\end{array}$ & $\begin{array}{c}95 \% \\
\text { CI }\end{array}$ & $\begin{array}{c}\text { Coefficient of } \\
\text { determi- } \\
\text { nation }\end{array}$ & $p$ value & Significance \\
\hline 1. & $\begin{array}{l}\text { Normalized score FPU } \\
\text { with Power score FPU }\end{array}$ & 0.51 & $\begin{array}{c}0.21 \text { to } \\
0.72\end{array}$ & 0.26 & $0.0019 * * *$ & $\mathbf{V S}$ \\
\hline 2. & $\begin{array}{l}\text { Normalized score MPU } \\
\text { with Power score MPU }\end{array}$ & 0.19 & \begin{tabular}{|c|}
-0.15 \\
to 0.49 \\
\end{tabular} & 0.03 & 0.2811 & NS \\
\hline 3. & $\begin{array}{c}\text { Normalized score FPU } \\
\text { with Normalized score } \\
\text { MPU }\end{array}$ & 0.40 & $\begin{array}{c}0.08 \text { to } \\
0.65\end{array}$ & 0.16 & $0.016 *$ & $\mathbf{S}$ \\
\hline 4. & $\begin{array}{l}\text { Power score FPU with } \\
\text { Power score MPU }\end{array}$ & 0.84 & $\begin{array}{c}0.70 \text { to } \\
0.91\end{array}$ & 0.70 & $<0.0001 * * * *$ & ES \\
\hline
\end{tabular}

FPU- Full Push Up, MPU- Modified Push Up, S- Significamt, QS- Quite Significant, NS- Not Significant 
Journal of Exercise Science \& Physiotherapy Vol. 15 No. 2 (July to December) 2019

ISSN: 0973-2020 (Print) I I OR Impact Factor $=6.502 \quad$ ISSN: 2454-6089 (Online)

Table 4. Correlation between Closed kinetic chain upper extremity stability test (CKCUEST) with hand dexterity using Perdue Pegboard

\begin{tabular}{|c|c|c|c|c|c|c|}
\hline & $\begin{array}{l}\text { Correlation between } \\
\text { variables }\end{array}$ & $\begin{array}{l}\text { Correlation } \\
\text { coefficient } \\
\text { ( r) }\end{array}$ & $\begin{array}{c}95 \% \\
\text { CI }\end{array}$ & $\begin{array}{r}\text { Coefficient of } \\
\text { determination }\end{array}$ & P value & Significance \\
\hline 1. & $\begin{array}{l}\text { Normalized score FPU } \\
\text { with Both hands pegboard }\end{array}$ & 0.31 & $\begin{array}{l}-0.02 \\
\text { to } 0.58\end{array}$ & 0.09 & $0.0722 * *$ & QS \\
\hline 2. & $\begin{array}{l}\text { Normalized score FPU } \\
\text { with Assembly pegboard }\end{array}$ & 0.38 & $\begin{array}{c}0.05 \text { to } \\
0.63\end{array}$ & 0.14 & $0.254 *$ & $\mathbf{S}$ \\
\hline 3. & $\begin{array}{l}\text { Normalized score MPU } \\
\text { with Both hands pegboard }\end{array}$ & 0.29 & \begin{tabular}{|c|}
-0.04 \\
to 0.57
\end{tabular} & 0.08 & $0.0853 * *$ & QS \\
\hline 4. & $\begin{array}{l}\text { Normalized score } \\
\text { MPU with Assembly } \\
\text { pegboard }\end{array}$ & 0.48 & $\begin{array}{c}0.18 \text { to } \\
0.71\end{array}$ & 0.23 & $0.0033 * * *$ & VS \\
\hline 5. & $\begin{array}{l}\text { Power score FPU with } \\
\text { Both hands pegboard }\end{array}$ & 0.29 & $\begin{array}{l}-0.04 \\
\text { to } 0.57\end{array}$ & 0.08 & 0.0891 & NS \\
\hline 6. & $\begin{array}{l}\text { Power score FPU with } \\
\text { Assembly }\end{array}$ & 0.08 & \begin{tabular}{|l|}
-0.25 \\
to 0.41
\end{tabular} & 0.008 & 0.6149 & NS \\
\hline 7. & $\begin{array}{l}\text { Power score MPU with } \\
\text { Both hands }\end{array}$ & 0.26 & $\begin{array}{l}-0.08 \\
\text { to } 0.55\end{array}$ & 0.06 & 0.1336 & NS \\
\hline 8 & $\begin{array}{l}\text { Power score MPU with } \\
\text { Assembly }\end{array}$ & 0.12 & \begin{tabular}{|l}
-0.22 \\
to 0.44
\end{tabular} & 0.01 & 0.4977 & NS \\
\hline
\end{tabular}

FPU- Full Push Up, MPU- Modified Push Up，S- Significamt, QS- Quite Significant, NS- Not Significant

Discussion

In the present study we found that the posture was at risk of injuries, preventive measures need to be planned for the rifle shooters. On comparison between Left Rapid upper limb Assessment (RULA) and Right Rapid upper limb Assessment (RULA), Table 1 and Figure 1 shows that Right upper extremity was at a higher risk with higher mean and standard deviation score of Rapid upper limb assessment (RULA) score (7) when compared with Left upper extremity which has a lower Rapid upper limb assessment (RULA) score of $(6.79 \pm 0.44)$ thereby indicating that Left upper extremity is at a lower risk of injury. The results of the present study shows that according to Rapid upper limb assessment (RULA) scoresheet, Left upper limb needs change and further investigation, while Right upper limb needs to implement changes and investigate for any postural risk in Rifle shooters. 


\section{Journal of Exercise Science \& Physiotherapy Vol. 15 No. 2 (July to December) 2019 ISSN: 0973-2020 (Print) $\quad \mathrm{I}_{2} \mathrm{OR}$ Impact Factor $=6.502 \quad$ ISSN: 2454-6089 (Online)}

On comparison between Left Rapid entire body assessment (REBA) and Right Rapid entire body assessment (REBA), Table 2 and Figure 2 shows that right entire body is at higher risk with higher mean and standard deviation of right REBA score $(8.61 \pm 0.77)$ as compared to left REBA score $(6.97 \pm 0.52)$ thereby indicating lower risk of injury on left limbs and trunk of the shooter than right side. According to Rapid entire body assessment (REBA)scale, Left side entire body is at medium risk of injuries, needs change in posture and further investigation is suggested while Right side body is at high risk, needs to be investigated and implement changes to prevent postural risk of injuries.

Table 5 shows a correlation between Closed kinetic chain upper extremity stability test (CKCUEST) Normalized score of Full push up and Closed kinetic chain upper extremity stability test (CKCUEST) Power score Full push up is statistically very significant $(\mathrm{r}=0.51, \mathrm{p}=0.0019)$. While Correlation between Closed kinetic chain upper extremity stability test (CKCUEST) Normalized score modified push up and Power score modified push up was found not significant ( $\mathrm{r}$ $=0.19, \mathrm{p}=0.2811)$. Correlation between Closed kinetic chain upper extremity stability test (CKCUEST) Normalized score of full push up and modified push up is significant $(r=0.40, p=$ 0.0164). Correlation between (CKCUEST) Power score Full push up and (CKCUEST) Power score modified push up was extremely significant $(\mathrm{r}=0.84, \mathrm{p}<0.0001)$. As shown in Table 3 there is significance between the variables of endurance, Normalized score and Power score of Closed kinetic chain upper extremity stability test (CKCUEST), both variables are individually important. Full push up and Modified push up both are relevant to endurance and can be used for training endurance.

As shown in Table 4 Correlation between Normalized score of Closed kinetic chain upper extremity stability test (CKCUEST) and different task of perdue pegboard are statistically significant. Relations were significant between Normalized score FPU with both hands pegboard $(\mathrm{r}=0.31, \mathrm{p}=$ 0.0722), Normalized score FPU with Assembly pegboard $(r=0.38, p=0.254)$, Normalized score MPU with both hands pegboard $(\mathrm{r}=0.29, \mathrm{p}=0.0853)$, Normalized score MPU with Assembly pegboard $(\mathrm{r}=0.48, \mathrm{p}=0.0033)$.

Mixed results were found in correlation between (Normalized score and Power score with full push up and modified push up) Closed kinetic chain upper extremity stability test (CKCUEST) and different task of perdue pegboard. Endurance and hand dexterity variables were found to be different attributes and independent of each other and hence no correlation was found. Thus, both these variables are different skills and need to be assessed and trained as an independent skill.

Training influences rifle shooters, but there is variability in response to training depending on many factors which influence performance .

To summarize our results of the present study, $10 \mathrm{~m}$ air Rifle Shooters were found prone to postural risk of injuries (Right > Left). Endurance and hand dexterity were found to be different attributes and independent of each other. Individual variables of Closed kinetic chain upper extremity stability test (CKCUEST) Normalized score and Power score were found to be relevant and important for endurance which could be used for endurance training. Upper extremity stability training need to be incorporated in rifle shooters. Sports specific dexterity need to be trained for optimizing performance. 


\title{
Journal of Exercise Science \& Physiotherapy Vol. 15 No. 2 (July to December) 2019 ISSN: 0973-2020 (Print) I IOR Impact Factor =6.502 ISSN: 2454-6089 (Online)
}

\section{Conclusion}

Rifle shooters are at postural risk with respect to their standing shooting stance. With the help of Rapid upper limb assessment (RULA) scale and Rapid entire body assessment (REBA) scale, this study shows that right side of the body was more affected than the left side of the body, rifle shooters need to investigate and implement changes that is to improve upper extremity stability, endurance and dexterity as they are at a higher risk of injury. Preventive strategy needs to be adopted. No correlation was found between Rapid upper limb assessment (RULA) and Rapid entire body assessment (REBA). There was significant correlation between Normalized score of CKCUEST and Power score of CKCUEST. Significant correlation was found between Normalized score of CKCUEST and hand dexterity. No correlation was found between Power score of CKCUEST and hand dexterity.

\section{References}

Ball K, Best R, Wrigley T. Body sway, aim point fluctuation and performance in rifle shooters: inter-and intraindividual analysis. Journal of sports sciences. 2003 Jan 1;21(7):559-66.

Corlett N, McAtamney L. Rapid upper limb assessment (RULA). InHandbook of Human Factors and Ergonomics Methods 2004 Aug 30 (pp. 86-96). CRC Press.

Gianikellis, K. (2000). Instrumentation and measurement methods applied to biomechanical analysis and evaluation of postural stability in shooting sports. In ISBS-Conference Proceedings Archive (Vol. 1, No. 1).

Goldbeck TG, Davies GJ. Test-retest reliability of the closed kinetic chain upper extremity stability test: a clinical field test. Journal of Sport Rehabilitation. 2000 Feb;9(1):35-45.

Goran Maksimovic.2019.The Fundamentals of Olympic Rifle Shooting. Available at_https://www.issfsports.org/theissf/academy/e_learning/rifle.ashx Accessed at March 01-2019

Hoffman MD, Gilson PM, Westenburg TM, Spencer WA. Biathlon shooting performance after exercise of different intensities. International journal of sports medicine. 1992 Apr;13(03):270-3.

Hignett S, McAtamney L. Rapid entire body assessment. InHandbook of Human Factors and Ergonomics Methods 2004 Aug 30 (pp. 97-108). CRC Press.

Ihalainen S, Kuitunen S, Mononen K, Linnamo V. Determinants of elite-level air rifle shooting performance. Scandinavian journal of medicine \& science in sports. 2016 Mar;26(3):266-74.

Selinger Christine J.2009. The effect of weight and weight distribution on upper extremity muscular fatigue during static rifle aiming (Doctoral dissertation not published).

Sue H, Lynn M. Rapid entire body assessment (REBA). Applied Ergonomics. 2000;31:201-5.

\author{
Conflict of Interest: None declared
}

